\title{
RELACIÓN UNIVERSIDAD Y SOCIEDAD, PRENSA Y POLÍTICA EN LOS MOVIMIENTOS ESTUDIANTILES DE LOS AÑOS CUARENTA EN LA UNIVERSIDAD DE CARTAGENA
}

\author{
Dora Piñeres De La Ossa ${ }^{1}$ \\ Universidad de Cartagena. RUDECOLOMBLA. SHELA \\ dorapineres@yahoo.es
}

Recepción: 30/05/2008

Evaluación: 1/06-15/09/2008

Aprobado: 29/09/2008

Artículo de Reflexión

\section{RESUMEN}

Movimientos estudiantiles, prensa y política ha representado en la historia de las universidades, una constante en Colombia. El acceso a la prensa se constituyó en un privilegio como medio de divulgación que les otorgó representación y liderazgo en la lucha por sus ideales. El movimiento de los años cuarenta en la Universidad de Cartagena, dejó una impronta: si bien este medio permitió su reconocimiento, y las demandas académicas fueron sus razones iniciales, estuvieron mayormente interesados en involucrarse en la lucha política bipartidista de esos años sobre todo, del lado del liberalismo hegemónico del período, organizándose incluso en movimientos o comités a nombre del socialismo y comunismo; posiciones de izquierda que empezaban a permear las instituciones universitarias colombianas y la oposición conservadora, que se hizo cada vez más fuerte.

Palabras Claves: Prensa, protestas, movimiento estudiantil, federaciones, cátedra libre, comunismo, ideas democráticas, gobiernos fascistas.

\footnotetext{
${ }^{1}$ Doctora en Ciencias de la Educación RUDECOLOMBIA, Profesora Titular de la Universidad de Cartagena, Directora Grupo de Investigaciones UniversidadEducación Sociedad, Grupo A de Colciencias 2006. Investigadora sobre la Historia de la Universidad de Cartagena, Directora Cátedra Institucional Universidad de Cartagena, Coordinadora Académica Maestría Educación SUE Caribe.
} 


\title{
UNIVERSITY, SOCIETY, PRESS AND POLITICS RELATIONSHIP IN THE STUDENT MOVEMENTS OF THE 40s IN THE UNIVERSITY OF CARTAGENA
}

\author{
Dora Piñeres De La Ossa \\ Universidad de Cartagena. RUDECOLOMBIA. SHELA \\ dorapineres@yahoo.es
}

\begin{abstract}
Student's movement, press and politics have shown a constant in Colombia through the university's history. The access to press began as a privilege used as media of publicity which gave the student's movement representation and leadership in the fight for its ideals. The movement of the forties at the Universidad de Cartagena is not an exception. It was due to this means of communication that its acknowledgement was given and even if it didn't permit the academic demands, it was interested in becoming part of the political fight of those times. Left-wingers started to arise in Colombian universities and the conservative opposition became more dominant.
\end{abstract}

Key Words: Press, protests, pro liberal movement, federations, open cathedra, communism, democratic ideas, fascistic governments.

\section{INTRODUCCIÓN}

La relación universidad y sociedad, que han caracterizado coyunturalmente las luchas estudiantiles no sólo en el país, sino también como una constante en América Latina, se visiona en el movimiento de los años cuarenta en la Universidad de Cartagena, como una estrecha relación entre los grupos y sindicatos con clara expresión social y los jóvenes universitarios. Su relación con la prensa comercial de la ciudad jugó un papel de reconocimiento a los intereses estudiantiles otorgándoles importantes espacios para su divulgación con los ideales políticos bipartidistas del momento, en una Cartagena que experimentaba un proceso de modernización lento en comparación al que se venía dando en otras ciudades del país, expresado en la expansión urbana por fuera del sector amurallado, obras de infraestructura 
como el acueducto y el alcantarillado, inicios de pavimentación, el desarrollo y conexión a través de carreteras con el interior del país lo que impulsó su actividad portuaria, el crecimiento de la mediana industria y el fortalecimiento de una clase política bipartidista liberal y conservadora que tuvo una fuerte representación nacional. Sin embargo, la Universidad de Cartagena que era el principal centro de educación superior de la costa atlántica y prácticamente el único hasta 1945, cuando se fundó en Barranquilla el Instituto de Tecnología, ofrecía tan solo estudios de Medicina, Derecho y Bachillerato. Durante el período se registran a través de los diarios locales, informes oficiales, discursos de directivos y estudiantes de la Universidad de Cartagena que la describen como una institución anclada en la tradición y en el continuismo del modelo de la vieja universidad republicana que era necesario dejar atrás y enrumbarla por los caminos de la modernización, que era la propuesta de reforma que circulaba en el país sobre la educación superior. ${ }^{2}$ El trabajo se sustenta en fuentes primarias aplicadas dentro de la metodología de la Historia Social de la Educación

\section{Entre ideales de reformas y la seducción por el poder}

La filiación liberal de los estudiantes que participaron en estos movimientos no solo se reflejó en las manifestaciones en pro de una mayor libertad de pensamiento y en la admiración a proto hombres liberales, sino también en la vinculación y uso de sus publicaciones en la prensa comercial, en los que se reproducían sus propuestas y actividades, legitimando de cierta manera sus actuaciones y demandas. Mirada como una tendencia, evaluamos que desde los estudios sobre movimientos estudiantiles en la década del veinte se refleja este comportamiento, prueba de ello, fueron las continuas columnas de Luís Tejada y Germán Arciniegas ${ }^{3}$ en los periódicos liberales El Tiempo y El Espectador en Bogotá, lo que permite pensar que los movimientos estudiantiles de estos años no avanzaron mucho en independencia política, como ya lo precisa Archila" "En parte por el peso de la contradicción liberal conservadora en toda la vida nacional y además, porque aunque algunos estudiantes coquetearon con el socialismo, el bipartidismo fue la expresión mayoritaria de los jóvenes de esos años". 5

\footnotetext{
${ }^{2}$ PIÑERES DE LA OSSA, Dora. (2008): MODERNIDAD, UNIVERSIDAD Y REGIÓN El caso de la Universidad de Cartagena, 1920-1946. Tesis Doctoral RUDECOLOMBIA. Editorial Universitaria, Búhos Editores p. 330

${ }^{3}$ PIÑERES DE LA OSSA, Dora. (2000): "El Movimiento Renovador Estudiantil y las Reformas Universitarias en Colombia, 1920-1930" en Revista Palabra Facultad de Ciencias Sociales y Educación Universidad de Cartagena, No.1 (Septiembre, pp.78-90).

${ }_{4}^{4}$ ARCHILA, Mauricio.(1999): "Entre la academia y la Política: El Movimiento Estudiantil en Colombia, 1.920-1.974". En: Movimientos estudiantiles en la Historia de América Latina.

Ibídem., pp. 162-163
} 
Esta precaria autonomía política explica el que en los siguientes decenios, en los treinta, los movimientos estudiantiles perdieran visibilidad, aunque no cejaron en protestas y manifestaciones que buscaban concretar sus propuestas de reformas de la universidad colombiana, en los estrados del Congreso. Los liberales al asumir el poder en 1.930, involucraron las esperanzas de diversos sectores sociales, como los obreros, las mujeres y los estudiantes que añoraban beneficios de la política de modernización que proponía. Muchos de los estudiantes que participaron en los movimientos de los años veinte sucumbieron ante las ilusiones reformistas que ofrecían los liberales; incluso muchos de ellos se vincularon a los proyectos del partido, este fue el caso de ${ }^{6}$ Germán Arciniegas quien asumió la dirección del Ministerio de Educación Nacional en 1.939 y el de Gerardo Molina como rector de la Universidad Nacional de Colombia entre los años de 1.942 y 1.944.

Los movimientos estudiantiles de los años cuarenta, al igual que los que se dieron en los años veinte, no cejaron en demandas de mejoramiento académico que propendiera por la modernización de la universidad. Los diarios locales al iniciarse la década registraban una situación verdaderamente crítica de la universidad de Cartagena ante la cual los estudiantes, se pronunciaron a través de manifestaciones dispersas y aisladas ante las autoridades departamentales, considerando como las principales causas de la crisis universitaria la mala administración académica, la deficiencia de los recursos que destinaba el gobierno departamental para su sostenimiento y la persistencia del viejo mecanismo burocrático de nombramiento de profesores.

La ley 68 de 1.935, recogió mucho de los requerimientos estudiantiles de los años veinte; otorgó una mayor participación de los estudiantes en las decisiones que tomaran las directivas de las universidades a través de sus representaciones en los consejos estudiantiles y en los consejos superiores de las universidades, la diversificación de los programas académicos, la participación del estudiante en la marcha del proceso docente con trabajos de investigación y así mismo, ofreció a los estudiantes, unas mejores condiciones en la vida intra universitaria en su participación tanto en los programas de extensión cultural como los de bienestar estudiantil, lugares en los cuales se fomentaba la formación del estudiante en un amplio esquema de actividades culturales que estimulaba el contacto con la ciudadanía por medio de conferencias, exposiciones, publicaciones; se fomentaba la actividad deportiva, se les brindaban servicios médicos y residencias estudiantiles. Sin embargo algunas de estas concesiones no pasaron más allá de las fronteras de la 
Universidad Nacional y las universidades departamentales - como el caso de la Universidad de Cartagena- siguieron debatiéndose en medio de las constantes dificultades económicas y asumiendo algunas recomendaciones emanadas del Ministerio de Educación sobre los pensum de los programas.

\section{Movimientos estudiantiles por la defensa del liberalismo}

Los estudiantes de principios de los años cuarenta en la Universidad de Cartagena aun cuando reclamaban demandas académicas, estuvieron mayormente interesados en involucrarse en la lucha política bipartidista de esos años, sobre todo del lado del liberalismo hegemónico del período, organizándose incluso en movimientos o comités a nombre del liberalismo amenazado por las nacientes posiciones de izquierda que empezaban a permear las instituciones universitarias colombianas y, la oposición conservadora que se hizo cada vez más fuerte. Los hechos que suscitaron el movimiento pro liberal de los estudiantes de la Universidad de Cartagena, fueron la presencia del comunista Germán Viera como inaugurador de la Cátedra Libre en la Universidad el 9 de junio de 1944 y el intento de golpe de Estado a la administración de Alfonso López Pumarejo por algunos militares conservadores, en la ciudad de Pasto el día 9 de julio del mismo año. Estos acontecimientos afectaron notablemente la cotidianidad de la vida universitaria y de la ciudad.

En 1944 un grupo de estudiantes liderados por Apolinar Díaz Callejas, Jorge Navarro Patrón, Antenor Barboza Avendaño, Armando Luján, José Miguel Hernández Olivella de la facultad de Derecho, y Olegario Barboza de Medicina, se sintieron atraídos por la ideología comunista que empezaba a penetrar en el mundo latinoamericano y se vincularon estrechamente con sus ideales sociales y políticos. La relación con los líderes sindicales de la Federación de Trabajadores de Bolívar fue estrecha y también con los que militaban en el comunismo, de quienes recibieron clases de Marxismo en la Plaza del Pozo de Getsemaní, que era el sitio predilecto de las reuniones de estudiantes y sindicales para discutir sobre la causa obrera y campesina a través del lente del comunismo. Así recuerdan estas reuniones los estudiantes egresados de la Facultad de Derecho de esos años Apolinar Díaz Callejas y Jaime Angulo Bossa:

...Yo por ejemplo mantenía contacto intenso con la Federación de Trabajadores de Bolívar, iba a todas las reuniones y a las reuniones dirigentes de los dirigentes campesinos del Departamento de Bolívar aquí en Cartagena, yo iba a todas esas reuniones como parte del trabajo político en el campo y en los sindicatos, además del trabajo 
en la Universidad... nosotros no estábamos encerrados en la Universidad, salíamos de la Universidad, entonces tuve mucho contacto con los dirigentes sindicales importantes de esa época que ya mencioné Tomás Herazo Ríos, José Raquel Mercado, había un líder sindical extraordinario que era Emiliano Blanco Pautt, un moreno fuerte, un hombre de vigor, buen orador pero además era uno de los miembros del coro de la Catedral de Cartagena, todos los domingos cantaba en los coros, y cuando hacíamos reuniones y había un poco de trago, él cantaba; era una voz maravillosa... Por ejemplo yo como líder estudiantil y al mismo tiempo estudiante de izquierda me metí a la lucha campesina en el departamento y a la lucha sindical; yo fui una vez a Magangué, pasando mil dificultades a ver unos problemas de sindicatos portuarios de Magangué, como estudiante; y hablé en la plaza de Magangué de sindicatos portuarios. Yo mantuve muy buenas relaciones con la Fedenal- la más grande organización sindical del Río Magdalena que ha tenido Colombia- en toda la historia, era muy amigo personal de los dirigentes sindicales siendo estudiante... Apolinar Díaz Callejas 81 años. ${ }^{7}$

... Yo recuerdo en ese entonces que nuestra generación estaba muy influida por el Marxismo y nosotros, en el caso particular recibíamos clases de Marxismo como estudiantes en la Plaza del Pozo de Getsemaní, uno de nuestros profesores fue José Raquel Mercado, líder sindical... Nosotros estábamos vinculados a los sindicatos, había una unidad entre obreros y estudiantes, definida. Nosotros compartíamos con los trabajadores, íbamos a todos los barrios de Cartagena; en ese entonces el estudiantado era muy inquieto y había una gran solidaridad con los trabajadores... Te voy a contar una anécdota, en 1.948 cuando me gradué mi tesis se tituló "Ensayos sobre las revoluciones" y abajo decía "Teoría axiológica", esa tesis causó algún impacto en los sectores conservadores porque ya se había caído el partido liberal, no me querían graduar por que la tesis mía era política y no científica...

$$
\text { Jaime Angulo Bossa. } 79 \text { años }{ }^{8}
$$

Esta relación de vinculación de los asuntos estudiantiles con las causas sociales y sindicales, marca un perfil de clara conciencia social particular del movimiento de la época de estudio: La atracción que representó el

\footnotetext{
${ }^{7}$ Entrevista a DÍAZ CALLEJAS, Apolinar. (2003): Estudiante Facultad de Derecho 1939-1946

${ }^{8}$ Entrevista a ANGULO BOSSA, Jaime. (2002): Estudiante Facultad de Derecho 1940-1946
} 
comunismo para estos jóvenes provenía de diversas corrientes; por un lado, alimentado por el rechazo a los gobiernos fascistas que en ese momento se imponía en el mundo europeo y por el otro lado, de la conciencia de algunos estudiantes por las condiciones deplorables en la que vivía la clase obrera; Apolinar Díaz Callejas quien más tarde sería el fundador del Partido Socialista en el Departamento de Bolívar recuerda su formación en las ideas comunistas:

Desde Colosó, un pueblo encaramado en los Montes de María, llegué a Barranquilla a la Escuela Normal del Litoral Atlántico, donde inicié mi preparación para ser institutor, es decir, maestro de escuela. En los tres años largos de internado en la Normal teníamos una disciplina y prácticas de cuartel militar en ejercicios, caminatas y trotes diarios. Recorrimos a pié todo el Departamento del Atlántico en varias excursiones, morral a la espalda. Hicimos notable excursión a la Sierra Nevada de Santa Marta. Desde el filo de sus alturas se veían las luces de Barranquilla, Santa Marta, Cartagena y otros sitios. En la plantación de café de un gringo, había un comisariato. A los trabajadores les pagaban con fichas que servían para pagar en el comisariato y para nada más. Era doble negocio... Desde entonces quedé marcado con la lucha antifascista. Leí los periódicos de la Escuela y cuanto folleto o libro cayera en mis manos, en ese momento le tocó sufrir a Abisinia la invasión por los ejércitos fascistas italianos, la que sufrió la lenta muerte de Antonio Gramsci en los calabozos de Mussolini, desde ese entonces fui parte de la generación de la lucha contra el fascismo... Leí libros revolucionarios como "La Madre" de Máximo Gorki, el Materialismo Histórico de Nicolai Bujarín, el Origen de la Familia, la Propiedad Privada y el Estado, y el Anti-Dühring de Federico Engells, el Manifiesto Comunista y algo más de Marx y de otros pensadores...Con este modesto bagaje de inquietudes intelectuales y políticas llegué a la Universidad de Cartagena

Los jóvenes comunistas, contaban con el apoyo de algunos líderes sindicales de la Federación de Trabajadores de Bolívar entre ellos José Raquel Mercado, Tomás Herazo Ríos y Emiliano Blanco Pautt; solicitaron al rector de la Universidad de Cartagena, Miguel A. Lengua permiso para traer al comunista Germán Vieira a que dictara una conferencia sobre historia de Colombia en el Paraninfo de la Universidad. Este hecho suscitó un movimiento estudiantil en defensa del partido liberal, respaldado por la mayoría de los estudiantes que consideraban al comunismo como una amenaza a "la ideología roja imperante en el mundo universitario". Jóvenes de diferentes facultades lanzaron voces de protesta en la prensa para rechazar la conferencia del comunista Vieira. Se conformó un comité permanente denominado 
"anticomunista" dirigido por los estudiantes de Derecho Alcides Angulo Passos y Elías Gómez Cáceres. El 7 de junio de 1944 este comité dirige una carta al rector de la universidad ${ }^{9}$ pidiendo que se le negara al grupo de estudiantes comunistas, la presencia de Vieira en el Paraninfo, aduciendo que éste no poseía título universitario, lo que era una manifiesta violación al reglamento interno de la universidad que establecía que los conferencistas tuvieran título universitario como requisito indispensable para el ejercicio de la Cátedra Libre.

La rectoría pasando por alto la petición generalizada de los estudiantes cedió el paraninfo a Vieira para que dictara su conferencia, aduciendo que negar el espacio a esta conferencia era negar los fundamentos en los que se sostenía el ejercicio de la "Cátedra Libre" que significaba libertad de pensamiento y de discusión. El día 9 de junio cuando inicio su conferencia el líder marxista, se hizo presente la policía por orden de la rectoría para prevenir cualquier brote estudiantil, lo que provocó la ira del estudiantado quienes en su mayoría se pronunciaron contra Vieira dando vivas a la "Gran Colombia" y dando abajos al comunismo. Por su parte algunos sindicatos de la ciudad militantes del comunismo agredieron a algunos estudiantes. El diario el Fígaro reprodujo la protesta estudiantil citando el caso del sindical José Raquel Mercado, quien intentó agredir de hecho a un estudiante de la facultad de Medicina. Al final la conferencia no pudo ser concluida y los estudiantes marxistas llevaron a Vieira a que continuara su disertación en el Teatro Heredia. Apolinar Díaz Callejas recuerda ese episodio de ésta manera:

En la conferencia de Vieira nos agarramos a trompadas en el paraninfo con los pro fascistas (refiriéndose a los estudiantes pro-liberales) y eso culminó en una gran conferencia en el Teatro Heredia. Allá culminó el acto con una gran manifestación por las calles de Cartagena... ${ }^{10}$

La presencia de Vieira en la Universidad de Cartagena generó como vimos un movimiento pro liberal de parte de los jóvenes universitarios, que se vio fortalecido un mes después con el intento de golpe de Estado perpetrado por los militares conservadores a Alfonso López Pumarejo en la ciudad de Pasto, pero el movimiento que había iniciado en contra del comunismo, se expresó luego en contra de las acciones del ala radical del conservatismo a quienes denominaban- naziconservadores ${ }^{11} \mathrm{y}$ en este momento los jóvenes liberales que en el mes de junio habían criticado al

\footnotetext{
${ }^{9}$ A.H.C. El Fígaro, Cartagena 8 de junio de 1944. p. 1

${ }^{10}$ Entrevista DÍAZ CALLEJAS, Apolinar, estudiante de Derecho 1944.

${ }^{11}$ La expresión Naziconservadora venía de la crítica que el estudiantado planteaba a las dictaduras Nazista y Fascista que empezaban a decaer en el mundo europeo con las revoluciones democráticas.
} 
comunismo, hacen alianzas con los jóvenes militantes de este partido que para este mes sufre una transformación en sus bases ideológicas e incorpora a su programa la defensa de la democracia denominándose "Partido Socialista Democrático", siendo su Fundador y Director del mismo en el Departamento de Bolívar, el estudiante de Derecho Apolinar Díaz Callejas. En la columna "La Universidad y sus transformaciones" del Diario de la Costa se publica un escrito referenciado como "Partido Socialista Democrático"12 en el que los jóvenes liberales explican su alianza con este comunismo "renovado" en las bases democráticas. Los estudiantes dejaron en claro que su alianza con el Partido Socialista Democrático surge de esa reevaluación de las ideas democráticas por este partido, que es una de las banderas bajo la cual se organiza la juventud liberal para defender la legitimidad de la administración liberal en el poder:

La nueva etapa histórica que inicia el partido comunista está como lo dijo Gilberto Vieira, en mayor acuerdo con la realidad colombiana. Los comunistas laboran por llegar a la unión y a la inteligencia de los partidos democráticos en todos los países, aceptan su rejuvenecimiento práctico de las ideas democráticas y la revalidación de la ideología liberal misma. Defender al Partido Socialista Democrático de las interpretaciones que se le han hecho, no significa definirse con ellos, con su programa e ideas, es preciso comprender el carácter patriótico y la trascendencia social del partido en colaboración con el liberalismo militante." Como decía Rafael Uribe Uribe "El liberalismo debe renovar la caduca doctrina individualista en las canteras inagotables del socialismo

Los estudiantes liberales en alianza con los comunistas para contrarrestar la oposición buscaron consolidar la doctrina liberal en el claustro universitario, a partir del supuesto de fortalecer los principios democráticos frente a los movimientos subversivos de la oposición, que empezaban a permear la institución y además, se interesaron en prevenir al núcleo proletario contra las rebeliones antidemocráticas, como la perpetrada en Pasto, cuyo fin a su juicio, solo ocasionaría "el derrumbe de un gobierno constituido legítimamente y por lo tanto, el desquiciamiento de las instituciones jurídicas". Además, a través de la prensa liberal, convocaban al proletariado y a los estudiantes a apoyar la presidencia de López que había involucrado en sus programas de gobierno la causa obrera y estudiantil. En carta de fecha 10 de julio ${ }^{13}$ publicado en el Diario de la Costa en su edición del 11 del mismo mes, los estudiantes bajo la autodenominación de "demócratas" ofrecen su apoyo a la administración liberal en la lucha contra la oposición conservadora:

${ }^{12}$ A.H.C. Diario de la Costa. Cartagena 11 de agosto de 1944. La Universidad y sus Transformaciones. Partido Socialista Democrático. Página Editorial.

${ }^{13}$ A.H.C. Diario de la Costa. Cartagena 11 de Julio de 1944. 
Los suscritos estudiantes demócratas de la Universidad de Cartagena declaramos: nuestra más encendida voz de protesta contra el frustrado golpe de Estado encabezado por el teniente Diógenes Gil en la ciudad de Pasto y encaminado a desconocer el orden constitucional establecido.

La juventud de la Universidad de Cartagena quiere hacer saber de una vez por todas, su inquebrantable fe democrática. El golpe de Estado de la ciudad de Pasto desdice de nuestra tradición democrática y solo puede comprenderse como un eslabón más en la ya poderosa cadena que viene construyendo el Nazismo derrotado en los campos de Europa por intermedio del falangismo tropical. Como sucede felizmente que la juventud colombiana no ha decidido aún uncir su porvenir al de las naciones totalitarias y quienes antes por el contrario quieren vivir en toda su intensidad la vida democrática.

La juventud colombiana tampoco puede olvidar en estos días oscuros que ahora se trata del más esclarecido de los defensores de los principios de libertad, el orden y la igualdad colombiana. De un desvelado apóstol de las clases obreras del país y del hombre que en el poder ha demostrado una más sincera compenetración con los problemas estudiantiles, de allí que nuestro interés de demócratas se halle justamente redoblado en este momento por nuestra profunda admiración por el caudillo y que simboliza la más alta de las virtudes de nuestro pueblo y a la vez su constante anhelo de superación y reforma.

No podemos cerrar estas líneas sin hacer una declaración beligerante de desafío a las huestes nazifascistas y sin hacer palpables nuestra voluntad irrevocable de la defensa de la democracia.

Queremos a la vez notificar en el gobierno de nuestro país y en especial al actual encargado del poder doctor Darío Echandía que estamos a sus órdenes para luchar a su lado en esta nueva batalla por la completa libertad de Colombia.

Universidad de Cartagena 10 de julio de $1944 .{ }^{14}$

\footnotetext{
${ }^{14}$ A.H.C. Diario de la Costa 11 de Julio. "Los Demócratas" firmado por estudiantes cedulados entre los que se cuentan Manuel S. Nule, Jaime Angulo Bossa, Jorge Mercado, Apolinar Díaz Callejas, Calixto Payares, Manuel Surge entre otros. Siguen firmas. Ver también en PIÑERES DE LA OSSA, Dora. (2003): "La facultad de filosofía y letras de la Universidad de Cartagena: Una propuesta social para la formación de los jóvenes de la región 1828-1949" en "La Cátedra Historia de la Universidad de Cartagena, mirar su historia para construir su futuro". Volumen 2, editorial Universidad de Cartagena, Octubre pp. 36-39.
} 
Frente a esta situación de amenaza de la democracia, la región caribe a través de los grupos estudiantiles no solo de Cartagena sino también los de Santa Marta y Barranquilla, constituyeron comités de juventudes liberales en alianza, como un frente electivo ante la dirección Nacional del Partido liberal, en contra de los desmanes de la reacción conservadora. El objetivo de estos comités, era realizar una divulgación de la ideología liberal como orientadora de las clases obreras, la atención al problema social surgido de la escasez y carestía de los alimentos en la Costa Atlántica en esta década, contando con la colaboración del Partido Socialista Democrático. En el Diario de la Costa en la columna "La Universidad y sus Transformaciones" se hace referencia a la conformación de estos comités de juventudes liberales en el litoral atlántico:

La Universidad y sus Transformaciones consolidado el frente de juventudes liberales en el litoral Atlántico. Espontáneamente las juventudes liberales de la República respondieron al estúmulo cuando el atentado de Pasto. En todos los departamentos se aglutinaron las juventudes liberales para dejar constancia de su apoyo al gobierno legitimante constituido y aprovechar una vez más para organizarse en un frente electivo contra los desmanes de la reacción- partido de oposición. En Santa Marta, Barranquilla y Cartagena se constituyeron comités de juventudes liberales cuyo objetivo es la divulgación ideológica liberal como orientación de las clases obreras, la atención del problema social surgido de la escasez y carestía de los alimentos en la Costa Atlántica, en fin, la conjuración oportuna de los manejos nebulosos del partido de oposición con la inapreciable colaboración del partido comunista en la convergencia total de sus ideas con las nuestras, de su plan de acción con el nuestro. ${ }^{15}$

Por otra parte y contrarrestando la dinámica social, estudiantil y política de las juventudes liberales, algunos estudiantes a través de la prensa trataron de dejar en claro una posición apolítica, exponiendo ante la opinión pública "la eterna fantasía de querer representar siempre lo académico", ${ }^{16}$ por ello repudiaban toda ingerencia que tendiera imprimirle al movimiento una apariencia política y protestaban contra aquellos que los acusaban de apoyar a algún candidato o de defender un sistema político en particular. En el periódico el Fígaro aparecen varios artículos que permiten visualizar esta

15 A.H,C. Diario de la Costa. Cartagena 4 de agosto de 1944 Página Editorial: Universidad y sus Transformaciones. Consolidado el frente de juventudes liberales en el litoral atlántico.

${ }^{16}$ ALVARADO, María de Lourdes. (1999): "La Universidad Libre primer movimiento estudiantil del Méjico independiente (1875)". en Movimientos estudiantiles en la Historia de América Latina. Coordinadora Renate Marsiske. Centro de Estudios sobre la universidad (CESU), Plaza \& Janés. Editores, y Universidad Nacional y Autónoma de Méjico, Méjico. Volumen No. 1. p. 65 
posición. En la edición del 21 de Julio del 1940 aparece el escrito "La Política y La Universidad" firmado bajo las iniciales I. V .M.:

La política y la Universidad": La política leímos alguna vez suele ser vidrio no solo de aumento o de disminución, sino máquina que trastorna la posición de las cosas, como aquel aparato que inventó un físico de California y con el cual los árboles, las gentes y los edificios presentaban sus imágenes invertidas. No invierte la política la posición de las cosas como el pervertido aparato, sino que es también ácido que disuelven los vínculos espirituales que unimos en haz de voluntades en la realización de nuestros ideales y en la conducción de nuestros destinos. Alma Mater y política son términos que se excluyen. Alma Mater significa compañerismo, amistad, comunidad de intereses e ideales. Política o politiquería, es tanto como decir, ambición viciosa: intereses ruines, individualismo y egoísmo. Los universitarios debemos desprendernos del yugo de la política bajo la cual yacemos asfixiados, porque no es digno de la juventud que es espíritu, permanecer vencida bajo los intereses bastardos de la materia. ${ }^{17}$

En este artículo dejaban en claro la exclusión de la política en las actividades estudiantiles, a través de conceptos como "intereses ruines", "individualismo", "egoísmo", "ambición viciosa"; que representaban a la Política y que se oponían al significado del Alma Mater, que definían los estudiantes con expresiones como: "comunidad", "intereses e ideales", "compañerismo" y "amistad". De alguna manera algunos estudiantes pretendían convencer a la opinión pública de su lejanía con la política que para ellos, era sinónimo -como vimos- de intereses ruines y ácido para los vínculos espirituales, y que en este momento, afectaba la paz de la sociedad colombiana, ya que para la década del cuarenta, los conflictos entre el liberalismo y el conservatismo y sus disidencias se hicieron muy fuertes. Conscientes del interés público por preservar la democracia, la paz en el país que se veía afectado con expresiones militares de golpes de Estado se interesaron por conquistar las simpatías del público aludiendo insistentemente al carácter academicista y apolítico del movimiento.

Posiblemente algunos jóvenes que hicieron parte del movimiento pro liberal del cuarenta y cuatro se sumaron a esos universitarios que pregonaban un divorcio entre política y universidad, quizá decepcionados por el rumbo que tomaban los conflictos entre liberales y conservadores, y la división irreconciliable del liberalismo de esos años con la incorporación de ideas de izquierda, que llevó al conservatismo al poder. Esta consideración viene de un

17 A.H.C. El Fígaro, 21 de Junio de 1940 No 1207, p. 4. "La Política y la

Universidad", firmado por I. V. M. 
artículo publicado en el Diario de la Costa en la edición de 30 de septiembre del año de 1.945 escrito por un candidato liberal a las elecciones de ese año, Braulio Henao Blanco,-egresado de la facultad de Bachillerato y Derechoquien en dicho artículo, parece cuestionar a la juventud universitaria que luchó del lado del liberalismo en años anteriores y que no rindió lo que se esperaba -en sus palabras-, y que se "encerró en los libros" volviendo la espalda a la "vida tumultuosa"- como así describe la situación social y política de estos años, Henao Blanco-. Planteando así mismo, que esta juventud sin interés por la política deviene en parte por la "política degenerada y corrupta" del departamento y del país en general que obligó a la juventud, a retirarse y encerrarse en la soledad de su devenir académico:

\section{"La Juventud en la Política":}

Aquí en Bolívar tenemos todavía una juventud universitaria que no se ha corrompido por la política, o más exactamente, por el ejercicio indecoroso de la politiquería. A pesar del halago con que se la tienta, hay en ella un sentido moral que la custodia y que la salva, y que la obliga a conservar en lo más alto de su parábola vital los colores duros de su dignidad. Con más tiempo y con más calma yo he de escribir una página sobre nuestra juventud que no ha rendido lo que de ella se esperaba en cuanto a capacidad batalladora y heroicidad beligerante. Pero bien sé que ha venido indiferente y que no ha sido por entrega maliciosa.

La juventud universitaria sobre todo, se ha encerrado en su castillo, después de hacer inútil el puente levadizo y ya en su imperio vigilada por los libros y solo preocupada con la meta de su propio ímpetu, se vuelve de espaldas a la vida, a esta vida tumultuosa que la espera y que será su campo de acción hasta morir.

Quizá tiene la culpa la política de este departamento en este caso, como en tantos otros... se corrompió tanto, y tanto se ha degenerado que la juventud sintió asco, asco y dolor ante tanta podredumbre. Y entonces, urgida por la meditación escogió la línea de menor resistencia.

Se retiró a su soledad que equivale a un metódico enfrentamiento de su voluntad combativa. Pero la juventud no acepta, como norma vital imprescriptible la nirvánica inquietud. $\mathrm{Su}$ ardimiento dionisiaco y apolineo, y embriaguez exuliante su denuedo. Nuestra juventud, en cualquier instante, domeñará su resignación transitoria y volverá sus aceros contra el sol. El camino más corto pasa por las estrellas, y su ruta es la ascensión natural 
por la escala de Jacob. La vida purificante es la vida peligrosa de la cuerda en el vacío con las pupilas que escruta el abismo para alcanzar la sabiduría de su misterio. ${ }^{18}$

A pesar de la posición apolítica que expresaron algunos estudiantes la mayoría de los jóvenes universitarios que participaron en los movimientos de los primeros años de la década del cuarenta, coquetearon con el liberalismo. La norma fue la falta de independencia política del estudiante de estos años, y la absorción de muchos de ellos por el liberalismo hegemónico de la época.

\section{La prensa conservadora ${ }^{19}$ y el movimiento estudiantil pro-liberal}

La prensa conservadora local El Fígaro y El Diario de la Costa abrieron sus páginas también a esta agitación estudiantil de corte liberal en la Universidad de Cartagena expresando en sus columnas editoriales su apoyo a la causa estudiantil, este apoyo se expresó en dos sentidos; por una parte en contra del ascenso del Tercer Partido en Colombia, el comunismo, y por el otro, en contra del liberalismo que le había dado impulso a las ideas comunistas en el país.

El periódico El Fígaro en su página editorial se pronunció a favor del movimiento estudiantil pro liberal en contra de la presencia del comunista Vieira en el claustro universitario y de paso rechazaba la presencia del comunismo en la Universidad Nacional que para el año de 1.944 tenía como rector a un comunista, Gerardo Molina, que según El Fígaro era considerado el más "comunista y agitador peligroso de estas ideas". En este sentido en la editorial del 10 de junio de 1.944 aparece el siguiente artículo:

\section{"El comunismo en la Universidad"}

Antes de reasumir el doctor Alfonso López fue nombrado Rector de la Universidad Nacional Gerardo Molina. Con este motivo hubo varias protestas por ser Molina comunista y agitador peligroso de estas ideas, las cuales están desarrollando con alarmantes celeridad en el país. El auge que el comunismo está tomando se debe principalmente al apoyo que el régimen liberal

\footnotetext{
18 A.H.C. Diario de la Costa. 30 de septiembre de 1945. p. 3. La nota del día (página editorial) "La juventud en la Política" Por HENAO BLANCO, Braulio.

${ }^{19}$ Se analiza solo la posición de la prensa conservadora frente a los movimientos estudiantiles de la Universidad de Cartagena a principios de la década del cuarenta, porque la posición de la prensa liberal no fue posible registrarla, debido a su ausencia en el período de estudio; en el Archivo Histórico de Cartagena el Periódico liberal El Porvenir solo aparece en los años de 1918 a 1928, y la Patria de 1918 hasta 1930.
} 
le presta. Así vemos que hace alianza con el partido comunista en elecciones para representantes, diputados y concejales, estimula las huelgas y los movimientos de las masas, y ahora, el régimen liberal le entrega la rectoría del pensamiento colombiano. No nos sorprende que en el camino de las concesiones irreflexivas y tontas, el gobierno resuelva abrirle las puertas de las salas de conferencias de nuestras universidades, a los secuaces del señor Molina. Ayer, por ejemplo vimos al señor Gilberto Vieira que según al decir de Juan Lozano y Lozano, es el más caracterizado y peligroso comunista colombiano, inaugurando en nuestro paraninfo la Cátedra Libre. Vieira anuncio una conferencia que tituló "Interpretación de la Historia de Colombia", y que bien pudo llamarse catecismo marxista, su disertación que al principio fue tolerada por un rasgo de natural cultura de nuestra juventud, fue interrumpida luego con el grito de protesta de los estudiantes. ${ }^{20}$

En el mismo periódico en la edición de junio 19 de 1.944 aparece en este mismo sentido un artículo titulado "Cátedra Libre"21 en el que se cuestiona la Extensión Universitaria al público de Cartagena a propósito de la conferencia de Vieira como sinónimo de "prostitución ideológica" mas no de libertad de juicio y de crítica:

\section{"Cátedra Libre"}

Así ha dado en llamarse, en esta nación de regreso hacia la barbarie, el inveterado sistema de envenenar el alma de la juventud. La etiqueta resultaría sin embargo magnífica, si fuese saludable el contenido, pero desgraciadamente entre nosotros "Cátedra Libre" es sinónimo de prostitución ideológica. En todas las universidades del mundo el Paraninfo es símbolo y sagrario.

El caso de Vieira en nuestra universidad es típico, viene él provisto de una especie de patente de curso, expedido nada menos que por el Ministerio de la Educación Nacional para ser política comunista desde la sala de actos de aquella institución venerable y porque alguno de los estudiantes que saben respetarse y velar por los fueros de las aulas expresaron su protesta contra semejante y afrentoso absurdo, airadamente como apenas es natural, se llega hasta decir de ellos, que son tipos de incultura y groseros ademanes porque dizque tratan de obstruir la expresión libre del pensamiento con actos de violencia. 
No señores, no, una cosa es la libertad de juicio, de crítica y de exposición sobre materias científicas y otra cosa inconsecuente e indigna es aprovechar impunemente la expresión cátedra libre para inculcar el virus de la política de partido o de secta. Es el caso desde el más alto sitio de una universidad." Luis Carlos González.

El Diario de la Costa por su parte dedicó una columna especial en su página editorial al movimiento estudiantil denominada "La Universidad y sus Transformaciones" dirigida por los estudiantes de Derecho Jaime Gómez O’Byrne y Hernando Mouthon, que aparecía diariamente. En esta columna se comentaba sobre las luchas de las juventudes universitarias de Cartagena al lado del liberalismo en contra de la oposición conservadora, y los sistemas políticos dictatoriales imperantes en algunos países europeos como el Nazismo y el Fascismo; sistemas que afectaban el desarrollo de la democracia, que habían tomado como bandera la agitación estudiantil en los primeros años de la década del cuarenta.

Este espacio que brindaba el Diario de la Costa a los estudiantes, tenía su explicación en la campaña conservadora, que su director Carlos Escallón estaba realizando para este año, con el fin de impedir una posible política de persecución a los conservadores por parte del gobierno liberal debido a los sucesos de Pasto. En una columna del Diario, su director invitaba a la juventud liberal de Cartagena y a los dirigentes del partido liberal, a crear un frente unido en contra de los nazi conservadores, como así se le llamaba a la disidencia conservadora que para estos años se movía entre movimientos pro-fascista que afloraban en el país con la aparición del Fascismo en Alemania e Italia, que propugnaban por una noción de razas superiores y razas inferiores, la negación del principio de igualdad de los hombres, de los derechos y libertades políticas que daban base a la Democracia, la exaltación de la guerra y la fuerza como motores de la historia ${ }^{22}$ En "Universidad y sus Transformaciones" en la editorial del 14 de julio de $1944^{23}$ aparece el siguiente comentario con respecto al intento de golpe de Estado, al gobierno de Alfonso López Pumarejo en Pasto:

La Universidad y sus Transformaciones.

El estudiantado fiel a los principios domésticos inmensa indignación ha causado el atentado contra la democracia perpetuado traidoramente en la persona del primer mandatario de la República Excelentísimo señor Presidente doctor Alfonso

\footnotetext{
${ }^{21}$ A.H.C. El Fígaro. Cartagena 19 de junio de 1944. p. 3 "Cátedra Libre".

22 A.H.C. Diario de la Costa. Cartagena, 10 de julio de 1944. p.1. Ver también JARAMILLO URIBE, Jaime. (1989): “La Educación durante los gobiernos liberales. 1930-1946. en Nueva Historia de Colombia, Bogotá, Editorial Planeta, p. 95.

${ }^{23}$ A.H.C. Diario de la Costa, Periódico conservador. Cartagena 11 de julio de

1944: "La Universidad y sus Transformaciones". p. editorial 2.
} 
López, en la ciudad de Pasto. El espíritu netamente democrático de los estudiantes de la Universidad de Cartagena dejó en una declaración decidida constancia de su airada protesta por el delito de lesa democracia y de lesa constitucionalidad cometido por el afortunadamente pequeño grupo de insurrectos que forman la capital de Nariño.

La conducta del estudiantado se encuentra a una distancia de encubrir una actitud de política solapada. Sino que del desconocimiento de los fundamentos constitucionales del Estado fácilmente surgirá un sistema de gobierno semejante sino igual a la de los empleados en naciones como en Alemania y España.

A las nuevas generaciones corresponde erigirse en defensores de las bases democráticas, porque a ellas les tocará más tarde dirigir la vida del país; y país situado en esos renglones nazi-fascistas es un país llamado al caos y los países en este estado caótico están destinados a ser los instrumentos de los demás".

De la misma manera se publica en la misma columna en la edición del 20 de julio, un escrito titulado "Vanguardia Liberal", ${ }^{24}$ en el que los estudiantes se solidarizan con la administración liberal de Alfonso López Pumarejo frente a la creciente reacción del conservatismo:

"Los acontecimientos que últimamente han agitado en forma violenta la estructura democrática del país ya tienen su resultado por cierto que totalmente distinto al esperado por los dirigentes de tan desafortunada reacción, la consolidación definitiva de las juventudes liberales en torno al actual régimen y el enarbolamiento de los auténticos principios democráticos por un beligerante comité de juventudes liberales. Del núcleo universitario convencido del ideario liberal ha surgido este frente sólido sin debilidades de especie alguno, sus miembros son todos enemigos de la política personalista y están resueltos a mantener los fueros del partido."

${ }^{24}$ A.H.C. Diario de la Costa, periódico conservador. Cartagena 20 de Julio de 1944. p. 2: "Vanguardia Liberal".

${ }^{25}$ Ibíd. A.H.C. Diario de la Costa. 


\section{CONCLUSIONES}

Tal como lo han venido asegurando los estudiosos sobre movimientos estudiantiles, en cuanto a las implicaciones del tinte político que marca la vida estudiantil, el movimiento de los años cuarenta, representado por un grueso grupo de jóvenes universitarios entre liberales y conservadores defendieron más que reformas académicas, los intereses políticos de los liberales en el poder y la nueva tendencia socio política del comunismo y socialismo siendo inicialmente voceros de los grupos sindicalistas y causas obreras de la ciudad y la región, para luego convertirse en líderes a nombre del liberalismo, de las expresiones marxistas y comunistas que empezaba a germinar en las claustros universitarios.

Contrario a lo que pudiera pensarse de que, los movimientos estudiantiles fueran afines con la identidad política de la prensa local, como ocurrió con el movimiento estudiantil liberal de los años veinte en Bogotá, para el caso de los grupos de los cuarenta en del departamento de Bolívar, la identidad política de los estudiantes -que era también mayoritariamente liberal- no obstaculizó como vimos sus expresiones en la prensa conservadora, que aunque fueran utilizadas por esta prensa para evitar la persecución liberal en los años cuarenta, permitió la libre expresión de los estudiantes liberales de la Universidad de Cartagena y toda la campaña pro liberal que estos realizaron durante la década.

Por lo tanto los movimientos estudiantiles no pueden ser examinados únicamente desde la perspectiva académico- universitaria, por importantes que fueran los cambios que pudieran abanderar en este campo, sino que es necesario considerarlo dentro de una clara relación con la sociedad inmersos, en contextos como los histórico-sociales, económico-político del país y de la región.

Los movimientos estudiantiles de los años cuarenta de la Universidad de Cartagena no pueden bajo ningún criterio, interpretarse como una fuerza de agitación al mero ámbito de la universidad, esta dinámica se circunscribió también a la cotidianidad de la ciudad, de la vida cotidiana de los universitarios, del entorno social y muy particularmente, de los intereses políticos de las clases dirigentes del momento. Desborda el acontecer pedagógico y adquiere matices de mucha importancia para el desarrollo social y cultural; hay que entender que, el movimiento más que a reformas educativas, respondió a un proceso muy amplio e intenso de agitación social. Sus líderes, historiados algunos de ellos sobre su permanencia o no en las dinámicas políticas, aseguraron que estas experiencias estudiantiles, fueron la fuerza que orientó su vida y permitió construir su perfil político. 


\section{FUENTES}

\section{Archivo Histórico de Cartagena}

A.H.C. El Fígaro, 21 de Junio de 1940 No 1207, p. 4. "La Política y la Universidad", firmado por I. V. M.

A.H.C. El Fígaro, Cartagena 8 de junio de 1944.p. 1

A.H.C. Diario de la Costa. Cartagena 11 de agosto de 1944. La Universidad y sus Transformaciones. Partido Socialista Democrático. Página Editorial.

A.H.C. Diario de la Costa. Cartagena 11 de Julio de 1944.

A.H.C. Diario de la Costa. 30 de septiembre de 1945. p. 3. La nota del día (página editorial)

A.H.C. El Fígaro. Cartagena 10 de junio de 1944. p. 3. "El Comunismo en la Universidad"

A.H.C. El Fígaro. Cartagena 19 de junio de 1944. p. 3 "Cátedra Libre".

A.H.C. Diario de la Costa. Cartagena, 10 de julio de 1944. p.1. Ver también Jaime Jaramillo URIBE. "La Educación durante los gobiernos liberales. 1930-1946. En Nueva Historia de Colombia Editorial Planeta, Bogotá 1989.p. 95.

A.H.C. Diario de la Costa, Periódico conservador. Cartagena 11 de julio de 1944: "La Universidad y sus Transformaciones". p. editorial 2.

A.H.C. Diario de la Costa, periódico conservador. Cartagena 20 de Julio de 1944. p. 2: "Vanguardia Liberal".

Entrevista a Apolinar Díaz Callejas (2003) Estudiante Facultad de Derecho 1939-1946

Entrevista a Jaime Angulo Bossa. (2002) Estudiante Facultad de Derecho 1940-1946.

\section{SELECCIÓN BIBLIOGRÁFICA}

ALVARADO, María de Lourdes. (1999): "La Universidad Libre primer movimiento estudiantil del Méjico independiente (1875)". en Movimientos estudiantiles en la Historia de América Latina. Coordinadora Renate Marsiske. Centro de Estudios sobre la universidad (CESU), Plaza \& Janés. Editores, y Universidad Nacional y Autónoma de Méjico, Méjico. Volumen No. 1. p. 65. 
PIÑERES DE LA OSSA, Dora. (2008): MODERNIDAD, UNIVERSIDAD Y REGIÓN. El caso de la Universidad de Cartagena, 1920-1946. Tesis Doctoral RUDECOLOMBIA, Tunja, Universidadd Pedagógica y Tecnológica de Colombia. RUDECOLOMBIA. Editorial Universitaria, Búhos Editores.

PIÑERES DE LA OSSA, Dora. (2000) “El Movimiento Renovador Estudiantil y las Reformas Universitarias en Colombia, 1920-1930" en Revista Palabra Facultad de Ciencias Sociales y Educación. Universidad de Cartagena, No. 1 (Septiembre).

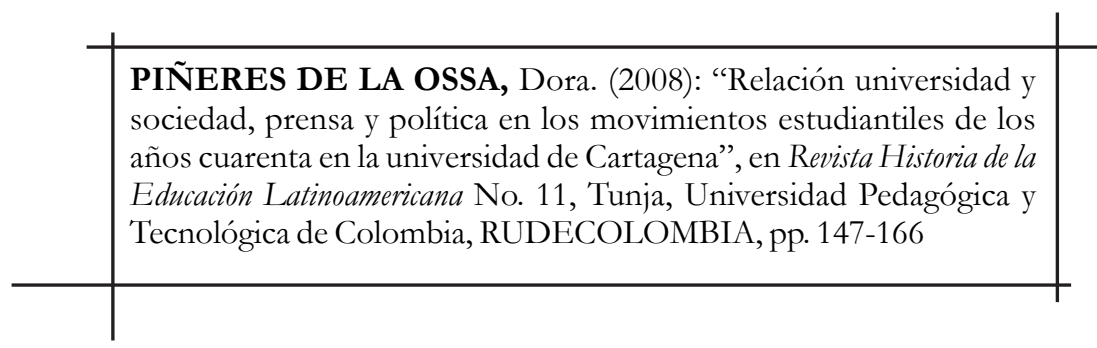

